\title{
Allocation of distributed generation and capacitor banks in distribution system
}

\author{
Oladepo Olatunde', Hasimah Abdul Rahman² \\ ${ }^{1,2}$ Centre of Electrical Energy Systems (CEES), Institute of Future Energy (IFE), Universiti Teknologi Malaysia (UTM), \\ Malaysia \\ ${ }^{1}$ Electrical and Electronic Engineering Department, Osun State University, Nigeria
}

\begin{tabular}{l} 
Article Info \\
\hline Article history: \\
Received Jul 8, 2018 \\
Revised Sep 9, 2018 \\
Accepted Sep 23, 2018 \\
\hline Keywords: \\
Adaptive particle swarm \\
optimization (APSO) \\
Capacitor banks \\
Distribution generation \\
Distribution system \\
Inertial weight \\
Voltage profile
\end{tabular}

\section{Corresponding Author:}

Hasimah Abdul Rahman,

Centre of Electrical Energy Systems (CEES),

Institute of Future Energy (IFE), Universiti Teknologi Malaysia (UTM),

81310 Johor Bahru, Malaysia.

Email: hashimahar@utm.my

\begin{abstract}
Voltage profile and power losses on the distribution system is a function of real and imaginary power loading condition. This can be effectively managed through the controlled real and reactive power flow by optimal placement of capacitor banks (CB) and distributed generators (DG). This paper presents Adaptive Particle Swarm Optimization (APSO) to efficiently tackle the problem of simultaneous allocation of DG and $\mathrm{CB}$ in radial distribution system to revamp voltage magnitude and reduce power losses. The modification to the conventional Particle Swarm Optimization (PSO) was achieved by replacing the inertial weight equation (W) in the velocity update equation, based on the particle best experience in the previous iteration. The inertial weight equation is designed to vary with respect to the iteration value in the algorithm. The proposed method was investigated on IEEE 30-bus, 33-bus and 69-bus test distribution systems. The results show a significant improvement in the rate of convergence of APSO, improved voltage profile and loss reduction.
\end{abstract}

Copyright $\odot 2019$ Institute of Advanced Engineering and Science. All rights reserved.

\section{INTRODUCTION}

The global increase in electrical power demand and the natural depletion in fossil fuel had necessitated the alternative sources of power generation [1]. The conventional method of transmission line upgrading is highly capital demanding with limited expansion in power capacity. In modernized distribution power system planning and operation, (DG) with microgrid (MD) had being a viable alternative and solution to power challenges [2]. DG, equally known as dispersed generation annexes small-scale technologies that can be powered by renewable energy sources for the production of electricity at users' vicinities. Technical advantages of renewable generation include reduction of pollution, power loss minimization, voltage stability enhancement and reliability improvement in distribution network. It can be modelled as induction and synchronous generators depending on its expected operation mode, either to generate reactive power only or generation of both real and reactive power [3]. DG are modeled at unity power factor to deliver active power sources. The involvement of non-programmable renewable resources raises many technical issues in the operation of modern power distribution networks. With conventional radially structured distribution networks, some technical challenges limit the integration of DG units: increase fault current magnitude, possible reserve power flow, ampacity violations and voltage variation from the operation limit [4].

Conventionally, capacitor banks (CB) are placed on distribution system for reactive power compensation. It is a reactive load generator. Its utilization benefits includes: minimization of power 
reduction due to losses, power factor regulation and maintenance of voltage regulations on load buses of the network [5]. Power loss reduction and voltage deviation improvement are significant and influential on the operation of distribution network, in supplying economical and high-quality power supply to consumer load $[5,6]$. Sizing and allocation of DG units with capacitor banks demands thorough investigation to avoid abnormal rise in voltage on distribution feeders, line overloading and uneconomical investment cost. Therefore, evaluating the optimal penetration level, DG location along with capacitor banks for power quality improvement, while maintaining required operating condition is imperative [8].

About ten years ago, different research papers had been published on optimal location and sizing of DGs [9]. Appreciable researchers targeted integration of capacitor banks in distribution system [10]. However, some recent papers focus on optimal sizing and placement of DGs along with capacitor banks on power distribution system. In addition, PSO had been convincingly implemented in power system researches and other engineering fields [11]. It was clearly shown that PSO performed better, faster and accurate in comparison to other methods [12]. The velocity equation of PSO was modified in [13] by addition of new terms and evaluation of difference in the global best and local best of particles. It outperformed other PSO modification in term of convergence speed, quality of accuracy when tested on various system models. An adaptive PSO was presented in [14], the particle velocity is adjusted using the inertial weight strategy such that the best fitted particle navigated in comparison to speed inspired low fitted particles. In [15], the optimum simultaneous DG and capacitor placement was presented, considering power loss minimization as a fitness function. The method was tested on standard IEEE bus system. The authors in [16] presented an algorithm for optimal allocation of DG using improved Genetic for IEEE-33 bus distributed system to compute the best performing reactive power control variables for active power loss reduction and maximize voltage profile. The method reduced the multi-objective function into single objective to avoid the complexity involved in multi-objective problem. In [17], the load variations is considered to capture the system dynamic nature. The loss sensitivity factors was used to evaluate and determine the bus where compensation is required. Thereafter PSO was employed to evaluate the capacities of the capacitor banks to be placed. For the varying sensitivity factors: reduced power losses with better energy conservation was recorded. Comparative analysis of PSO and other techniques like genetic algorithm, tabu search and hybridization method shows that PSO produces better saving, reduced losses and ameliorated voltage profile.

This work presents the simultaneous DG and capacitor bank allocation in distribution network, while considering minimization of power losses and voltage profile maximization as fitness function. The voltage boundary limits are considered as system constraints. The modification was achieved by replacing the inertial weight $(\mathrm{w})$ in the velocity update base on the success achieve in exploration and exploitation of the search space. The technical achievement of a particle in its current location is determined to decide choice of inertial weight for such particle for the next iteration. In addition, the particles trailed the sensitivity of the buses to enhance better convergence.

\section{RESEARCH METHOD}

As shown is 1 gives the proposed mathematical model for the simultaneous DG and capacitor placement considering the fitness function as minimization of total active power losses

$$
\operatorname{Min} f=\sum_{l=i}^{N L} K_{i} R_{i} I_{i}^{2} \quad i \in N L
$$

Such that

$$
\begin{aligned}
& K_{i}\left|I_{i}\right| \leq I_{l \max } \quad i \in N L \\
& V_{i \min } \leq V_{i} \leq V_{i \max } \quad i \in N L \\
& P_{i}\left|P_{i}\right| \leq P_{i \max } \quad i \in N L \\
& Q_{c_{\text {max }}} \leq Q_{\text {total }}
\end{aligned}
$$


Where

$\mathrm{I}_{\mathrm{i}}$ is line current in branch i

$\mathrm{R}_{\mathrm{i}}$ is resistance of branch $\mathrm{i}$

$V_{i}$ is node voltage at node $i$

$\mathrm{P}_{\mathrm{i}}$ is real power in branch $\mathrm{i}$

Qi is reactive power in branch $i$

$\mathrm{Q}_{\text {cmax }}$ is maximum size of $\mathrm{CB}$

$\mathrm{Q}_{\text {total }}$ is total reactive power demand

$\mathrm{K}_{\mathrm{i}}$ represents the topological status of the branches

$\mathrm{N}$ is sum of branches

$\mathrm{NL}$ is the set of branches

The voltage stability proposes potential of distribution network within voltage limit against the variation in load demand. The fitness function is expressed as 6 .

$$
f_{2}=\min _{i \in 2, \ldots, N}\left\{V_{s}^{4}-4 V_{s}^{2}\left(R_{i} P_{L i}+X_{i} Q_{L i}\right)-4\left(X_{i} P_{L i}+R_{i} Q_{L i}\right)^{2}\right\}
$$

Modeling of DG unit presented in PQ node mode adopted are:

a) DG as 'Negative PQ load' model of PQ mode. The DG is simply modeled as a constant active (P) and reactive $(\mathrm{Q})$ power generating source. The given values of the $\mathrm{DG}$ model are real $\left(\mathrm{P}_{\mathrm{DG}}\right)$ and reactive $\left(\mathrm{Q}_{\mathrm{DG}}\right)$. The modified load at bus $\mathrm{i}$ with $\mathrm{DG}$ unit is expressed as:

$$
\begin{gathered}
P_{\text {load }, i}=P_{\text {load }, i}-P_{D G, i} \\
Q_{\text {load }, i}=Q_{\text {load }, i}-Q_{D G, i}
\end{gathered}
$$

b) DG as 'Constant Power Factor' model of PQ mode. Synchronous generator and power electronic based DG units was modeled as constant power factor model. The power output was regulated by controlling the exciting current and trigger angles for synchronous generator and power electronic base DGs respectively. As shown in 9 and 10 give the reactive power and equivalent current injection of the DG respectively.

$$
\begin{aligned}
& Q_{i D G}=P_{i D G} \tan \left(\cos ^{-1}\left(P F_{i D G}\right)\right) \\
& I_{i D G}=I_{i D G}^{r}\left(V_{i D G}\right)+j I_{i D G}^{i}\left(V_{i D G}\right)=\left(\frac{P_{i D G}+j Q_{i D G}}{V_{i D G}}\right)^{*}
\end{aligned}
$$

Where, $I_{i D G}^{r}$ is real component of DG current injection,

$I_{i D G}^{i}$ is Imaginary component of DG current injection.

c) The DG as PV node is commonly constant voltage model. The given values of the DG model are the real power and bus voltage magnitude. In order to maintaining constant voltage, voltage variation with time is maintained approximately zero by injecting required reactive power. In this work, the DG was configured to supply both the real and reactive power while the CB supplied the reactive power.

The backward/forward sweep (BFS) technique for load flow analysis was adopted for the work. The ratio of resistance to reactance $(\mathrm{R} / \mathrm{X})$ in distribution system is high and the conventional power flow methods like the Newton-Raphson cannot be perfectly fitted, taking into cognizance their method of derivation. Therefore, it may experience convergence difficulty in solving power flow in radial distribution network. In the BFS technique, the network system is assumed to be balanced and is represented by an equivalent single line diagram. The analysis starts from one branch to another in a sequential way until all the branches in the feeders have been traced. The bus voltages, except the source bus, are initially assumed to be one (1) pu at angle zero (0). Based on these voltages and given real and reactive power, the branch currents, proceeding from the end buses to the source, are evaluated and saved (Backward Sweep). It is however, requires a sequential procedure to ensure the network branches are rightly traced. The branch incidence table was used to avoid skipping of busses and branches. Then, branch currents, are computed to calculate the real and reactive power loss on the network. The current at the source end is now obtained using 11: 


$$
\begin{aligned}
& \left.I=\sum_{\substack{i=1 \\
i \neq s}}^{n} P_{i}+\sum_{\substack{j=1 \\
i=1 \\
i \neq j}}^{n} P_{\text {Loss. } i j}+j\left(\sum_{\substack{i=1 \\
i \neq s}}^{n} Q_{i}+\sum_{\substack{j=1 \\
i=1 \\
i \neq j}}^{n} Q_{\text {Loss. } i j}\right)\right) / V_{s}^{*} \\
& Z_{i j}=R_{i j}+j X_{i j} \\
& V_{\text {Drop. } i j}=V_{j}-V_{i}=I_{i j} Z_{i j} \\
& P_{\text {Loss. } i j}=I_{i j}^{2} R_{i j} \\
& Q_{\text {Loss. } i j}=I_{i j}^{2} X_{i j}
\end{aligned}
$$

Where:

$\sum_{i=1}^{n} P_{i}$ is summation of active load power connected to entire consumer' end buses;

$\sum_{i=1}^{n} Q_{i}$ is summation of reactive load power connected to the entire consumer' end buses;

$\sum_{j=1}^{n \neq s} P_{\text {Loss. } i j}$ is summation of branch (ij) real power loss across the all network branches;

$i=1$
$i \neq j$

$\sum_{j=1}^{n} Q_{\text {Loss.ij }}$ is summation of branch (ij) reactive power loss across the all network branches;

$i=1$
$i \neq j$

$V_{S}^{*}$ is the conjugate of the source voltage;

I is current at the source end;

$Z_{i j}$ is impedance of branch ij;

$R_{i j}$ is resistance of branch $\mathrm{ij}$;

$X_{i j}$ is reactance of branch $\mathrm{ij}$;

$V_{\text {Drop.ij }}$ is voltage drop across branch $\mathrm{ij}$

$V_{j}$ and $V_{i}$ are voltage at bus $\mathrm{j}$ and i respectively;

$I_{i j}$ is current through bus $\mathrm{i}$ to $\mathrm{j}$.

The forward sweep is then begins at the source to the end of the feeders to compute voltage drop using 13, current $\left(I_{i j}\right)$, real and reactive power losses using 14 and 15 respectively. The evaluated total power losses are compared to initial values computed by assuming one per unit voltage for all buses. If the difference exceeds the tolerance limits, the source current is re-computed using 11 , in terms of the newly obtained losses, and the path retracting operation is repeated. The computation procedure is repeated until the variation in losses between successive values of the source current is within the specified tolerance limit. The PSO particle's velocity and position is mathematically modeled as:

$$
v_{i}^{k+1}=w v_{i}^{k}+c_{1} \text { rand }_{1} \times\left(\text { pbest }_{i}-x_{i}^{k}\right)+c_{2} \text { rand }_{2} \times\left(\text { gbest }-x_{i}^{k}\right)
$$

Where $v_{i}^{k}$ is agent $\mathrm{i}$ velocity at iteration $\mathrm{k}, \mathrm{w}$ is weighting function, $c_{1}$ and $c_{2}$ are acceleration coefficients, rand is random number between 0 and $1, x_{i}^{k}$ and $x_{j}^{k}$ are agent $\mathrm{i}$ and $\mathrm{j}$ current position at iteration $\mathrm{k}$ respectively, pbest $t_{i}$ is the pbest of agent $\mathrm{i}$, and gbest is the gbest of the group. The particle position is updated using 17.

$$
x^{k+1}=x_{i}^{k}+v_{i}^{k+1}
$$

The weighting factor is expressed as

$$
w=w_{\max }-\frac{w_{\max }-w_{\min }}{\text { Itre }_{\max }} \text { Itre }
$$


Where $w$ is the weighting function, $w_{\max }$ and $w_{\min }$ are maximum and minimum weights, Itre $e_{\max }$ and Itre are maximum and current iteration respectively. The choice of inertia weight plays a significant role in the performance of the particle swarm optimization. The modification on the inertial weight (w) in the velocity update was based on the success achieve in exploration and exploitation of the search space. The technical achievement of a particle in its current location is determined to decide choice of inertial weight for such particle for the next iteration. In addition, the particles trailed the sensitivity of the buses to enhance better convergence.

The Figure 1 shows the proposed algorithm for the adaptive base PSO for simultaneous location of DG and CB. If the $\mathrm{P}_{\mathrm{D}}$ is the total power demand on distribution network. $\mathrm{Q}_{\mathrm{D}}$ is the total reactive power on the network. Therefore:

$$
S_{D}=P_{D}+Q_{D}
$$

$\mathrm{S}_{\mathrm{D}}$ defines the total network loading. Representing a particle by:

$$
P=\left[P_{1}, P_{2}, P_{3} P_{4}, \ldots \ldots . . P_{n p}\right]
$$

If $\mathrm{Nb}$ represent the number of buses on the network such that: $(\mathrm{b}=2,3,4 \ldots \mathrm{Nb})$ represent the possible location of DG or CB on the network. Thus:

$$
2 \leq L_{D G} \leq N b \text { and } 2 \leq L_{C B}<N b
$$

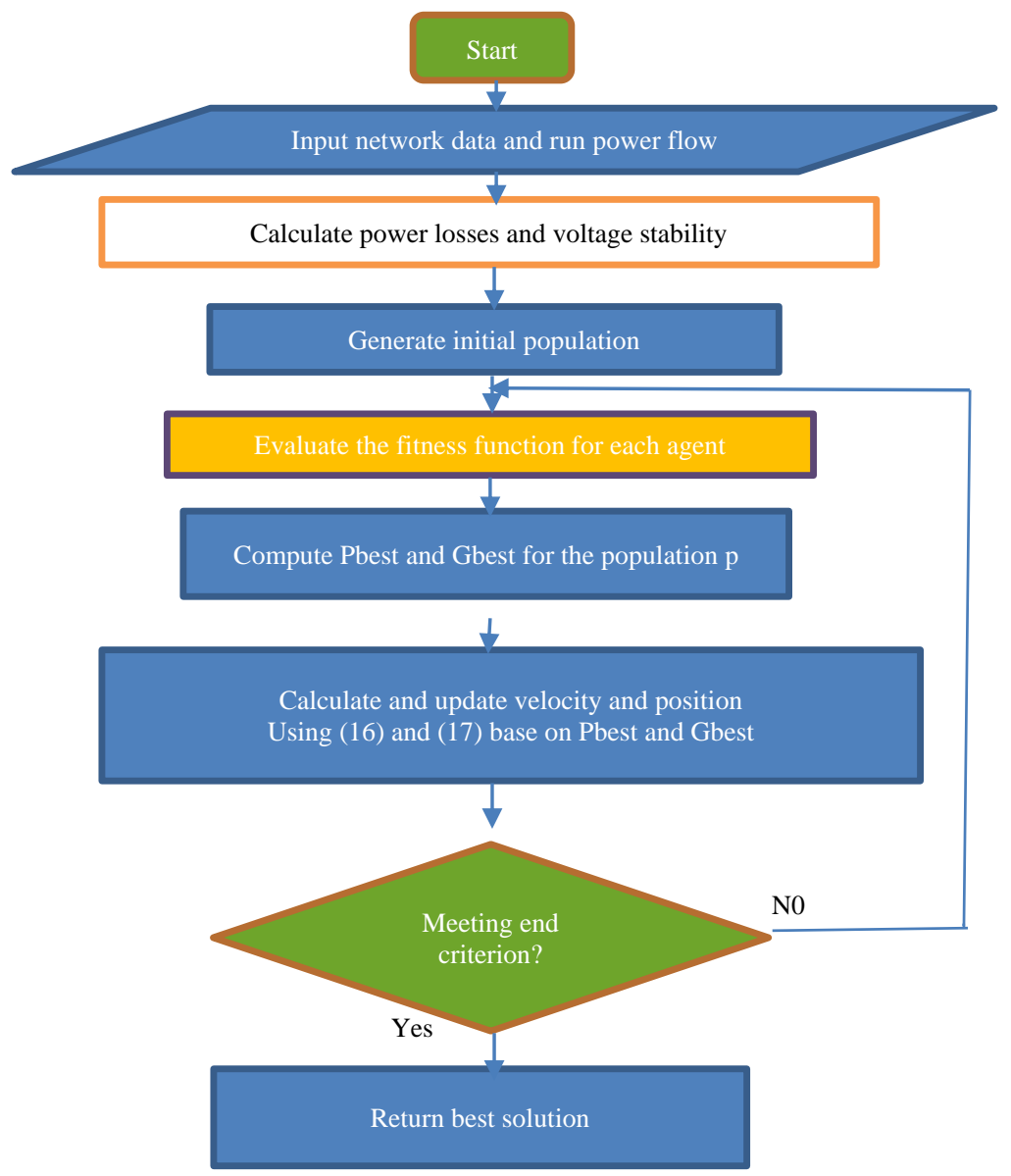

Figure 1. Flowchart of the proposed method

The structure of each particle is shown in Figure 2. 


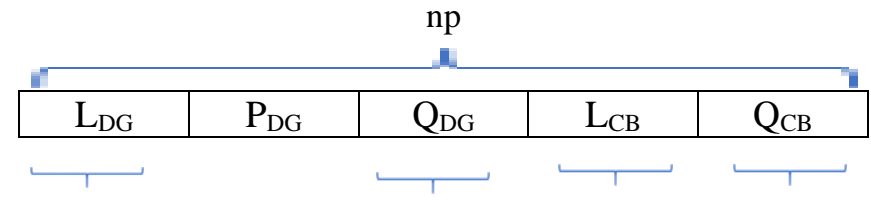

Figure 2. Structure of particle

$$
n p=n p_{1}+n p_{2}+n p_{3}+n p_{4}+n p_{5}
$$

$n p$ represents the total number of parameters in a given particle or dimension of particle.

Where:

$\mathrm{L}_{\mathrm{DG}}$ is location of $\mathrm{DG}$

$\mathrm{P}_{\mathrm{DG}}$ is real power of $\mathrm{DG}$

$Q_{D G}$ is reactive power of $\mathrm{DG}$

$\mathrm{L}_{\mathrm{CB}}$ is location of $\mathrm{CB}$

$\mathrm{Q}_{\mathrm{CB}}$ is reactive power of $\mathrm{CB}$

\section{RESULTS AND ANALYSIS}

The proposed algorithm is simulated using the IEEE 30, 33 and 69-bus radial network with base voltage of $12.66 \mathrm{kV}$ and the base apparent power is 10MVA. Figure 3 and Figure 4 show the single line diagram of 33-bus system and 69-bus system [18].

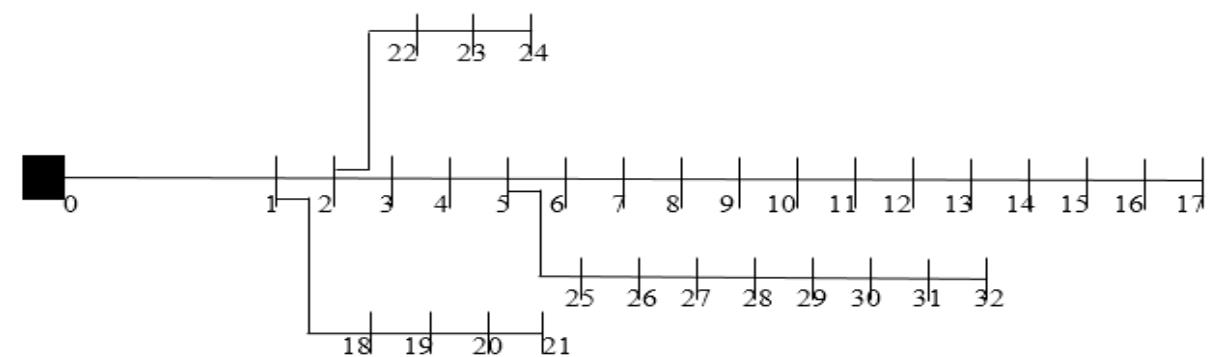

Figure 3. Single line diagram of 33-bus distribution test system

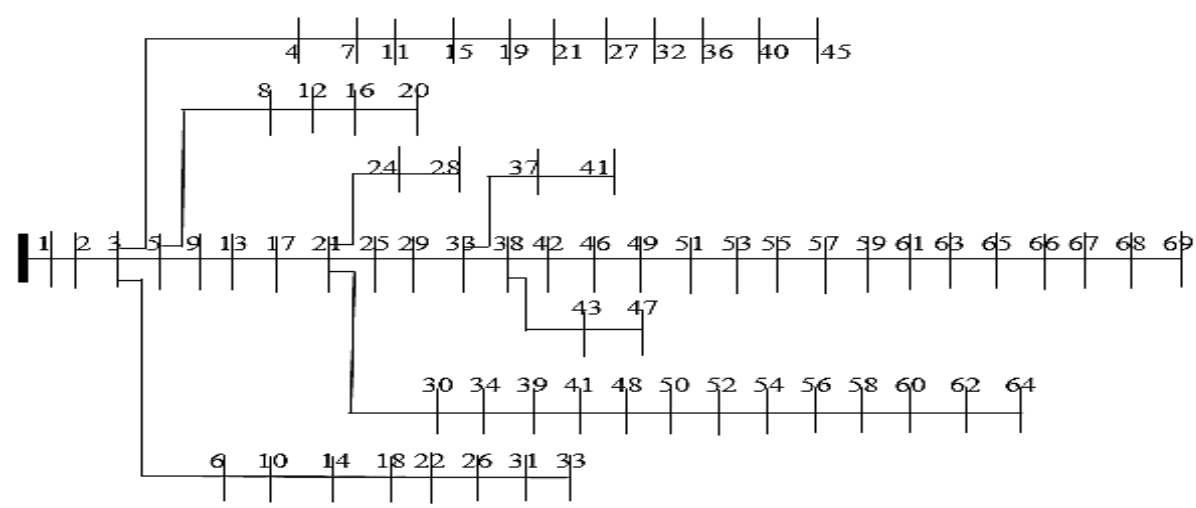

Figure 4. Single line diagram of 69-bus distribution test system

\subsection{Base Case System Analysis}

Initially, load flow analysis was carried out on 30-bus system for the determination of voltage profile and power loss. Total power loss is $0.0087+0.0026 \mathrm{i}(0.0091)$ in per unit. For 33-bus system, the total 
power loss of the system is $0.0027+0.0011 \mathrm{i}(0.0029)$ in per unit. The base case voltage of the 33-bus system before the integration of DG and CB into the network is presented in Table 1. The voltage magnitudes in Table 1 is plotted against their respective bus numbers is shown in Figure 5.

Table 1. Base Case Voltage for 33 Bus Network

\begin{tabular}{ccc}
\hline Bus no & Voltage without DG\&CB & \\
\hline 1 & $0.9860+0.0228 \mathrm{i}$ & 0.9863 \\
2 & $0.9752+0.0301 \mathrm{i}$ & 0.9757 \\
3 & $0.9696+0.0338 \mathrm{i}$ & 0.9702 \\
4 & $0.9642+0.0375 \mathrm{i}$ & 0.9649 \\
5 & $0.9489+0.0431 \mathrm{i}$ & 0.9499 \\
6 & $0.9440+0.0420 \mathrm{i}$ & 0.9449 \\
7 & $0.9404+0.0452 \mathrm{i}$ & 0.9415 \\
8 & $0.9348+0.0479 \mathrm{i}$ & 0.9360 \\
9 & $0.9295+0.0503 \mathrm{i}$ & 0.9309 \\
10 & $0.9288+0.0509 \mathrm{i}$ & 0.9302 \\
11 & $0.9277+0.0519 \mathrm{i}$ & 0.9292 \\
12 & $0.9220+0.0543 \mathrm{i}$ & 0.9236 \\
13 & $0.9195+0.0547 \mathrm{i}$ & 0.9211 \\
14 & $0.9182+0.0554 \mathrm{i}$ & 0.9199 \\
15 & $0.9169+0.0561 \mathrm{i}$ & 0.9186 \\
16 & $0.9146+0.0565 \mathrm{i}$ & 0.9163 \\
17 & $0.9140+0.0568 \mathrm{i}$ & 0.9158 \\
18 & $0.9855+0.0230 \mathrm{i}$ & 0.9858 \\
19 & $0.9820+0.0244 \mathrm{i}$ & 0.9823 \\
20 & $0.9812+0.0246 \mathrm{i}$ & 0.9815 \\
21 & $0.9805+0.0248 \mathrm{i}$ & 0.9808 \\
22 & $0.9719+0.0318 \mathrm{i}$ & 0.9724 \\
23 & $0.9655+0.0345 \mathrm{i}$ & 0.9661 \\
24 & $0.9624+0.0359 \mathrm{i}$ & 0.9631 \\
25 & $0.9476+0.0440 \mathrm{i}$ & 0.9486 \\
26 & $0.9460+0.0452 \mathrm{i}$ & 0.9471 \\
27 & $0.9382+0.0482 \mathrm{i}$ & 0.9394 \\
28 & $0.9328+0.0503 \mathrm{i}$ & 0.9342 \\
29 & $0.9307+0.0518 \mathrm{i}$ & 0.9321 \\
30 & $0.9265+0.0529 \mathrm{i}$ & 0.9280 \\
31 & $0.9255+0.0531 \mathrm{i}$ & 0.9270 \\
32 & $0.9252+0.0531 \mathrm{i}$ & 0.9267 \\
\hline & &
\end{tabular}

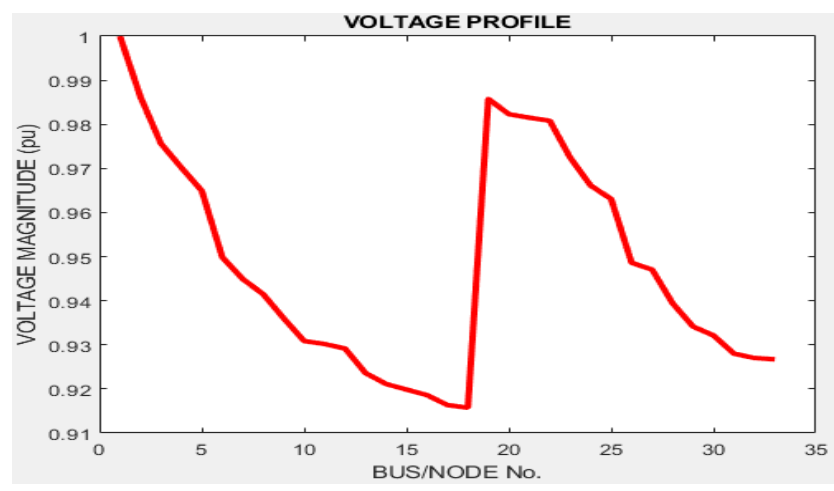

Figure 5. Voltage profile for 33-bus network

The branch profile for 33-bus system by plotting the current magnitude against their respective branch is shown in Figure 6. For 69-bus system, initial load flow was simulated to get the base voltage at each bus and the base total power loss of the system without placement of devices. The base case total power loss is $0.0238+0.0107 \mathrm{i}(0.0261)$ in per unit. The base case voltage magnitudes is plotted against their respective bus and that of the branch current profile is shown in Figure 7 and Figure 8. 


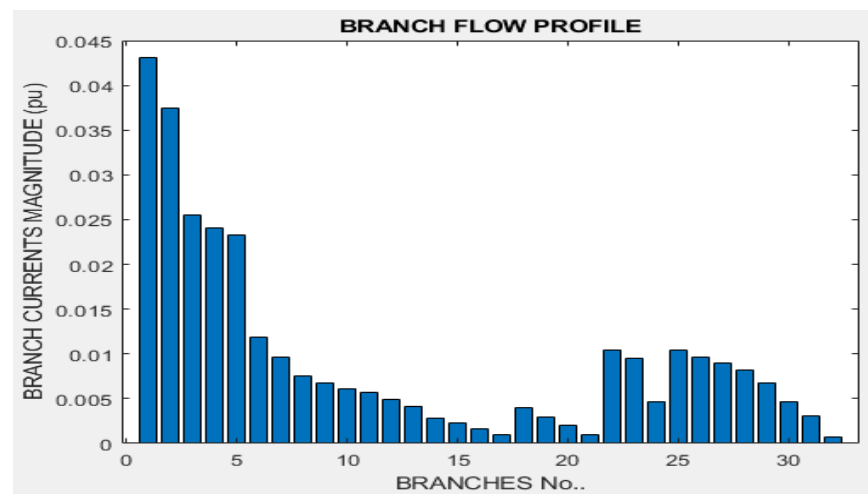

Figure 6. Current magnitude for 33-bus network

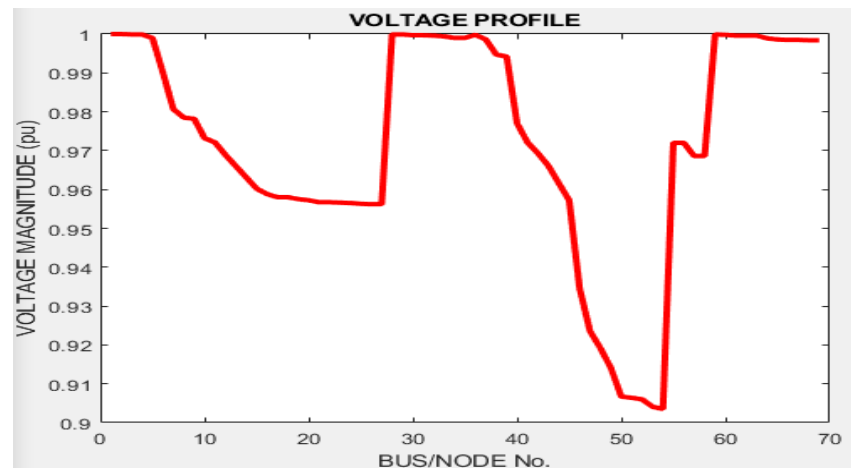

Figure 7. Voltage profile for 69-bus network

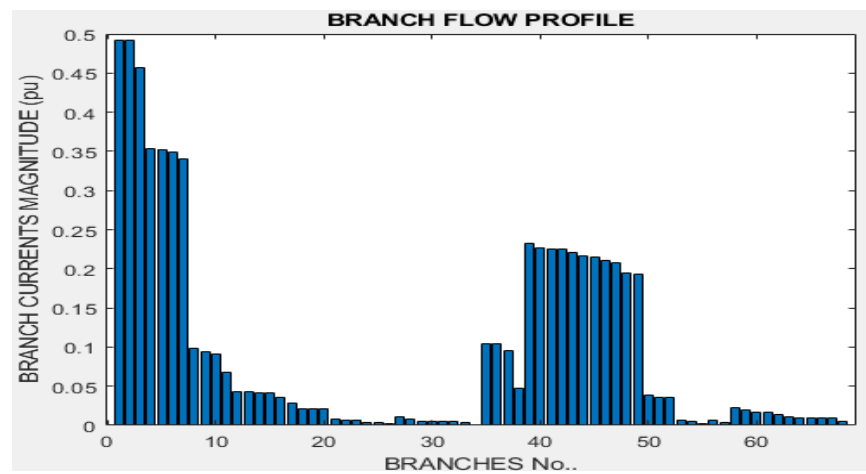

Figure 8. Current magnitude for 69-bus network

\subsection{Effects of DG and CB Placement}

Applying the proposed method for the optimum DG and CB locations with their corresponding sizes, the computed results are presented in Table 2. The effect of DG and CB placement is also evaluated by calculating the power system losses reduction and system voltage improvement. Table 3 shows effect of DG placement on network performance. The base case of 33-bus system and the improved voltage magnitude is shown in Figure 9.

There is an improvement in voltage profile after the placement of DG and CB on bus 26 and bus 21 respectively. The lowest voltage that is bus 17 with it voltage increases from 0.9158 to 0.9481 per unit voltage. This is an indication that the DG and CB installed has improved the voltages at each bus of the network. The blue line point out the base case voltage trend while the red line point out the voltage profile after DG and CB placement. The 69 bus base case voltage magnitude, and the corresponding improved voltage were plotted against their respective buses. The voltage profile plot is shown in Figure 10. 
Table 2. Application of Proposed Algorithm for Simultaneous DG and CB Placement and Sizing

\begin{tabular}{cccccc}
\hline \multirow{2}{*}{$\begin{array}{c}\text { Test } \\
\text { System }\end{array}$} & \multicolumn{5}{c}{ Proposed Method } \\
\cline { 2 - 4 } & $\begin{array}{c}\text { DG } \\
\text { Position }\end{array}$ & \multicolumn{2}{c}{ DG Size } & $\begin{array}{c}\text { CB } \\
\text { Position }\end{array}$ & $\begin{array}{c}\text { CB Size } \\
(\mathrm{kVar})\end{array}$ \\
\cline { 3 - 4 } & & $\mathrm{P}(\mathrm{kW})$ & $\mathrm{Q}(\mathrm{kVar})$ & & \\
\hline 30-Bus & 12 & 37.2 & 22853.9 & 17 & 3808.9 \\
33-Bus & 26 & 1.04 & 7356.6 & 21 & 2908.3 \\
69-Bus & 36 & 891.0 & 275340.8 & 42 & 209229.2
\end{tabular}

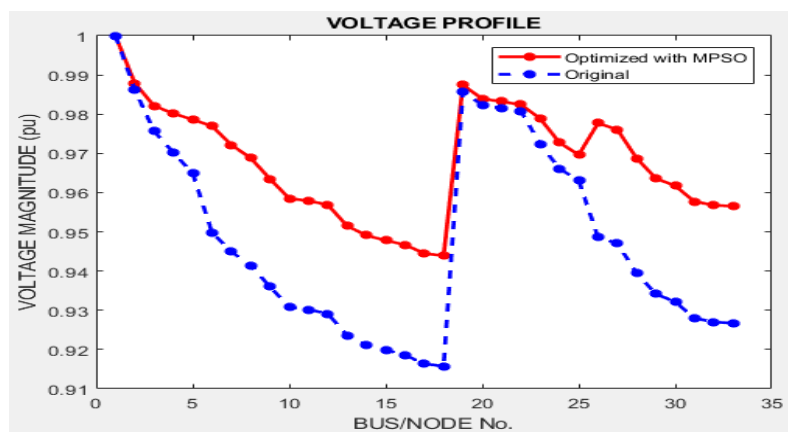

Figure 9. Voltage profile for 33-bus after placement

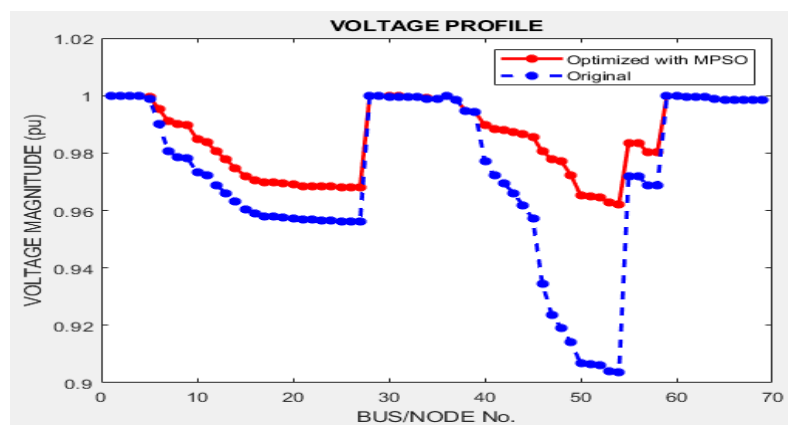

Figure 10. Voltage profile for 69-bus after placement

Table 3. Impact of Proposed Algorithm for Simultaneous DG and CB Placement and Sizing Test

System Proposed Method

\begin{tabular}{|c|c|c|c|c|c|c|c|}
\hline \multirow[t]{2}{*}{ System } & \multicolumn{2}{|c|}{$\begin{array}{c}\text { Power loss } \\
\text { Without DG \& CB }\end{array}$} & \multicolumn{2}{|c|}{$\begin{array}{c}\text { Power loss } \\
\text { With DG \& CB }\end{array}$} & \multirow{2}{*}{$\begin{array}{l}\text { \% Total } \\
\text { loss } \\
\text { reduction }\end{array}$} & \multirow[t]{2}{*}{$\begin{array}{c}\% \text { Voltage } \\
\text { improvement }\end{array}$} & \multirow[t]{2}{*}{$\begin{array}{c}\text { Simulation } \\
\text { Time }\end{array}$} \\
\hline & Ploss $(\mathrm{kW})$ & Qloss(kVar) & Ploss $(\mathrm{kW})$ & Qloss(kVar) & & & \\
\hline 30-Bus & 874 & 256 & 402 & 84 & $55.1 \%$ & $35 \%$ & $1.4816 \mathrm{~s}$ \\
\hline 33-Bus & 266 & 108 & 102 & 57 & $60.2 \%$ & $42 \%$ & $3.4909 \mathrm{~s}$ \\
\hline 69-Bus & 2383 & 1074 & 1191 & 482 & $50.9 \%$ & $45 \%$ & $11.1885 \mathrm{~s}$ \\
\hline
\end{tabular}

A significant improvement is observed in Figure 10 after DG and CB placement. Bus 53 has the smallest voltage of 0.9322 before DG and CB placement and have increased to 0.965 after the placement. The blue line point out the base case voltage trend while the red line shows the trend of the voltage after placement.

\subsection{Comparison of the Method with Existing Method and Network without DG and CB}

A comparative examination of the proposed method is further made with other optimization techniques in previous works for establishing its efficiency. More specifically, salient features such as convergence and technical improvement predicated the approach adopted in this work. This MPSO version was given enabling parameters to achieve optimal solution by extending iteration number as high as 1000 
with population of 200 particles, and equally achieve a better and fast convergence time of $1.4816 \mathrm{sec}$, $3.4909 \mathrm{sec}$ and $11.1885 \mathrm{~s}$ for 30-bus, 33-bus and 69-bus system respectively compare to [19]. PSO, multi objective genetic algorithm (MOGA) and biogeography based optimization (BBO) technique were used in [20]. The proposed DG and CB allocation method is also helpful for reduction of network power loss and voltage improvement with highest value of $60.2 \%$ and $45 \%$ respectively.

\section{CONCLUSION}

Optimal DG and CB placement problem has been solved by using Adaptive particle swarm optimization (APSO) technique. The modification was achieved by replacing the inertial weight (w) in the velocity update. The proposed location and size of active power and reactive power of DG with reactive power of CB had been computed by summing up the loads and losses of all the branches on the distribution network. Through the optimal allocation of DG and CB by the proposed technique, the active and reactive power losses are reduced and the system voltage profile improved.

\section{REFERENCES}

[1] Mogaligunta Sankaraiah1. Suresh Reddy S. Vijaya Kumar M. GWO based optimal reactive power coordination of DFIG, ULTC and capacitors. Indonesian Journal of Electrical Engineering and Computer Science. 2018; (11)3: 805-813.

[2] Mohan V. Alber T. Optimal sizing and sitting of distributed generation using Particle Swarm Optimization Guided Genetic Algorithm. International Conference on Intelligent Computing, Instrumentation and Control Technologies. 2017; (10)5: 709-720.

[3] Lakshmi Prasann., Jain A. Ranjith Kumar. Optimal Distributed Generation Placement Using Hybrid Technique. Asia Pacific Power and Energy Engineering Conference. 2017.

[4] Caldon R Coppa M. Sgarbossa R. Turri R. A simplified algorithm for OLTC control in active distribution MV networks. AEIT Annual Conference. 2013; 1-6.

[5] Olatunde O. Tola A. Power Quality Improvement in Electrical Distribution Network. American Journal of Engineering Research, 2016; (5)12: 224-227.

[6] Mashhadi O. Sadegh M. The influence of smart controller of the distributed generation sources and capacitor banks on loss minimization and profile improvement in the electricity distribution networks voltage," 20th Electrical Power Distribution Conference (EPDC). 2015; 272-276.

[7] Nabil Bin Muhtazaruddin. Distribution Power Loss Minimization via Distributed Generation, Capacitor and Network Reconfiguration. Indonesian Journal of Electrical Engineering and Computer Science. 2017; (5)3: 488.

[8] Kayal P. Ashish T. Chanda C. Simultaneous placement and sizing of renewable DGs and capacitor banks in distribution network. International Conference on Circuits, Power and Computer Technology. 2014; 607-611.

[9] Tan W. Hassan M. Majid M. Abdul Rahman H. Optimal distributed renewable generation planning: A review of different approaches. Renewable and Sustainable Energy Reveiws. 2013; (18): 626-645.

[10] Jegadeesan M. Simultaneous Placement of Multi-Dg Using Hybrid Optimization Method. IEEE International Conference on Innovations in Green Energy and Healthcare Technologies. 2017; 1-7.

[11] Raouf A. A multi-objective distributed generation allocation and sizing using swarm intelligence based algorithms. 19th IEEE Mediterranean Eletrotechnical Conference. 2018; 281-286.

[12] Mahajan S. Vadhera S. Optimal Sizing and Deploying of Distributed Generation Unit using a Modified Multiobjective Particle Swarm Optimization, IEEE Transaction on Industrial Application. 2016; (52)3.

[13] Singh S. A Review on Particle Swarm Optimization Algorithm, International Journal of Scientific and Engineering Research. 2014; (5)4.

[14] Ojha R. Das M. An Adaptive Approach for Modifying Inertia Weight using Particle Swarm Optimisation. International Journal of Computer Science. 2012; (9)5: 105-112.

[15] Aman M. Jasmon B. Solangi K. Bakar A. Mokhlis H. Optimum Simultaneous DG and Capacitor Placement on the Basis of Minimization of Power Losses. 2013; International Journal of Computer and Electrical Engineering. 2013, (5)5:516-522.

[16] Ahmadi A. Khademi H. Mousavi H. Hajizadeh A. Optimal Allocation of DG by using Improved Genetic for IEEE 33 Bus Systems. Technical Journal of Engineering and Applied Science. 2014;29-35.

[17] Mansour H. Abdelsalam A. Nabil M. Sallam A. Optimal capacitor banks allocation in distribution systems with distributed generators using antlion optimizer. 19th International Middle-East Power System Conference. 2017;19-21.

[18] Samir M. Dawoud. Xiangning Lin. Firas M. Qasim Kamil Mohsin. Hybrid Method for Optimal Placement of Multiple SPV Based Multiple RDGs in Microgrid System. Indonesian Journal of Electrical Engineering and Computer Science.2016; 4)2: 298-304.

[19] Gkaidatzis P. Bouhouras A. Doukas D. Sgouras K. Labridis D. Application and evaluation of UPSO to ODGP in radial Distribution Networks. International Conference on European Energy Mark. 2016.

[20] Hazem N. Elshahed M. A. Z. Osman H. Optimal Placement of Dispatchable and Non- Dispatchable Distributed Generation of Different Technologies. International Middle East Power Systems Conference. 2017;19-21. 